\title{
HUBUNGAN LINGKUNGAN BELAJAR DENGAN HASIL BELAJAR IPA SISWA KELAS V SDN 102028 KAMPUNG GELAM KABUPATEN SERDANG
}

\section{YENIMA WARUWU \\ (PGSD FKIP UNIVERSITAS KATOLIK SANTO THOMAS SU)}

\begin{abstract}
ABSTRACK
This study is a quantitative study with a population of 129 students in grade V SDN 102028 Kampung Gelam district of Serdang Bedagai with the number of respondents as many as 27 people. Data collection techniques used were questionnaires, documentation, and interviews. Student learning outcomes are influenced by various factors that occur in the learning process both internally and externally. One of the external factors that play a role in determining the success of student learning is the learning environment of family, school and community. Of the three learning environments concerned about how parents support children's learning, the facilities at school for learning activities and how students interact with others. Without the support of these three things, will make the learning process becomes hampered. Data analysis technique used is descriptive analysis technique while hypothesis test using product moment correlation test assisted by program of SPSS version 21. Based on the results of research, learning environment and student learning outcomes in general are in enough categories. Hypothesis test with a significance level of 5\% obtained results indicating that the school environment is positively and significantly correlated with student learning outcomes. Shown by the result of analysis of rhitung is bigger than rtabel $(0,504>0,381)$ and coefficient of determination $25 \%$. It can be concluded that between the learning environment and the learning outcomes have a positive and significant relationship. The results of this study are expected to be useful for students, parents, students, and principals. Proposed suggestion is that the learning environment should be created safely and comfortably so that the students' learning result will be optimal.
\end{abstract}

\section{Keywords: School Environment: Learning Outcomes}

\section{PENDAHULUAN}

\section{Latar Belakang Masalah}

Pendidikan memiliki peranan yang sangat penting dalam kehidupan dan kemajuan umat manusia. Pendidikan dapat menjadi sebuah kekuatan untuk mengubah tingkah laku manusia melalui penelitian dan pengajaran. Pendidikan dapat dikatakan sebagai suatu proses dalam rangka mempengaruhi siswa agar dapat menyesuaikan diri sebaik mungkin terhadap lingkungannya. Dengan demikian pendidikan akan menimbulkan perubahan dalam diri seseorang yang memungkinkan untuk berfungsi secara optimal dalam kehidupan masyarakat. Dalam pendidikan dibutuhkan pengajaran yang efektif yang bertugas mengarahkan proses agar sasaran dari perubahan itu dapat tercapai sesuai dengan yang diinginkan. 
Menurut Undang-Undang Nomor 20 tahun 2003 tentang Sistem Pendidikan Nasional, menjelaskan bahwa pendidikan adalah usaha sadar dan terencana untuk mewujudkan suasana belajar dan proses pembelajaran agar peserta didik secara aktif mengembangkan potensi dirinya untuk memiliki kekuatan spiritual keagamaan, pengendalian diri, kepribadian, kecerdasan, akhlak mulia, serta keterampilan yang diperlukan dirinya, masyarakat, bangsa dan negara.

Berdasarkan menurut UU tersebut menyatakan bahwa pendidikan adalah salah satu peranan yang sangat penting, untuk menciptakan generasi penerus bangsa yang cerdas serta berakhlak mulia. Dengan demikian, pendidikan dapat diperoleh dari mana saja, baik pendidikan formal maupun pendidikan non formal. Sekolah merupakan suatu lembaga pendidikan formal, yang sistematis telah merencanakan berbagai lingkungan. Lingkungan pendidikan yang menyediakan beragam kesempatan bagi siswa untuk melakukan berbagai kegiatan belajar sehingga para siswa memperoleh pengalaman pendidikan.

Pendidikan dapat membantu peserta didik untuk mengembangkan kemampuannya dalam berpikir kritis dan berpikir secara ilmiah. Pada dasarnya pertumbuhan dan perkembangan siswa tergantung pada tujuan pendidikan dan pengajaran guru, bakat yang telah ada sejak lahir dalam diri siswa akan tumbuh dan berkembang karena adanya pengaruh dari orang lain atau dari lingkungannya. Lingkungan dapat merupakan laboratorium untuk memperkaya pengajaran baik itu untuk guru ataupun siswa harus mengenal lingkungan dan memanfaatkannya secara fungsional dan maksimal dalam proses belajar mengajar.

Adapun lingkungan belajar siswa yaitu: 1) Lingkungan keluarga. Lingkungan keluarga merupakan pusat pendidikan yang utama dan pertama tetapi juga dapat menjadi faktor kesulitan belajar. Anak lahir dalam lingkaran keluarga dan dalam pemeliharaan orang tua. Di samping itu hubungan orangtua dan anak sangat berpengaruh dalam kemajuan belajar anak. 2) Lingkungan sekolah. Sekolah merupakan lembaga pendidikan formal yang memungkinkan seseorang meningkatkan pengetahuan dan mengembangkan bakat yang dimilikinya. 3) Lingkungan masyarakat. Masyarakat merupakan lapangan pendidikan yang luas dan meluas yaitu hubungan antara dua orangtua atau lebih yang tak terbatas. Untuk itulah lingkungan masyarakat mempunyai pengaruh terhadap keberhasilan belajar siswa. Karena lingkungan yang terstruktur dengan baik akan termotivasi sehingga anak dapat dan mau belajar.

Diketahui bahwa hasil pencapaian belajar yang baik tidak hanya pada satu faktor dari dalam diri siswa misalnya kondisi kesehatan, kecerdasan/intelegensi, bakat, minat dan motivasi, melainkan faktor dari luar yang mendukung prestasi atau hasil belajar siswa antara lain keluarga, sekolah, masyarakat dan keadaan lingkungan. Oleh karena itu lingkungan belajar perlu diperhatikan bagi setiap siswa, agar proses dan hasil belajar yang diperoleh sesuai dengan yang diharapkan. Bila lingkungan belajar siswa memadai maka akan mempengaruhi prestasi atau hasil belajar yang baik bagi siswa dalam proses belajar mengajar terutama dalam keseriusan dan konsentrasi. Dengan demikian dapat dipahami bahwa pengertian lingkungan belajar adalah segala sesuatu yang berada di sekitar siswa baik lingkungan sosial maupun lingkungan non sosial yang berpengaruh terhadap proses belajar siswa. Pembahasan dalam penelitian ini 
difokuskan pada pengaruh dari luar diri siswa seperti lingkungan belajar, fasilitas belajar, kenyamanan, kebersihan dan keindahan.

Hasil belajar adalah wujud dari usaha belajar yang dicapai seorang siswa berupa pengetahuan dan peningkatan kualitas perilaku dari ranah kognitif, afektif, dan psikomotorik yang tercapai melalui aktivitas siswa dalam proses belajar. Oleh karena itu, setiap sekolah atau lembaga yang melaksanakan pendidikan sebaiknya harus memiliki komponen belajar yang baik. Fasilitas yang lengkap pada hakikatnya akan mempermudah, mempercepat dan memperdalam pengertian siswa dalam menerima pembelajaran.

Hasil belajar yang baik tidak terlepas dari kondisi lingkungan belajar yang kondusif dan mendukung terjadinya proses belajar mengajar yang baik dan efektif. Kondisi lingkungan yang dimaksud ialah kondisi lingkungan keluarga, sekolah dan masyarakat itu sendiri. Lingkungan belajar sangat berperan penting dalam proses belajar siswa. Sarana dan prasarana yang berupa ruangan kelas harus mencukupi jumlah sekolah siswa yang ada disekolah tersebut, suasana rumah yang mendukung siswa untuk termotivasi dalam belajar, sehingga siswa dapat belajar dengan baik. Namun kenyataannya di lapangan sarana prasarana kelas yang ada belum memadai, dan dukungan motivasi dari orang tua siswa belum sepenuhnya didapatkan oleh peserta didik. Hal ini menyebabkan siswa kurang semangat dalam belajar.

Berdasarkan hasil observasi dan wawancara dengan guru wali kelas V Ibu Nina Mardiana, S.Pd yang dilakukan penulis di SDN 102082 Kampung Gelam, adanya hal-hal yang kurang mendukung selama proses pembelajaran antara lain: a) Hasil belajar siswa rendah, b) Lingkungan sekolah di pinggir jalan yang menimbulkan kebisingan oleh deru kendaraan bermotor, c) Kurangnya penggunaan media selama proses pembelajaran, d) Sarana dan prasana belajar yang terbatas, e) Kurangnya perhatian dan motivasi dari orang tua siswa. Hal ini menyebabkan siswa menjadi malas dan kurang motivasi belajar sehingga pencapaian hasil belajar menurun. Hal ini dipengaruhi oleh kondisi lingkungan yang kurang mendukung proses pembelajaran yang membuat hasil belajar siswa menurun. Karena lingkungan merupakan salah satu faktor dari luar yang mempengaruhi hasil belajar siswa menjadi baik. Baik itu lingkungan keluarga, sekolah maupun lingkungan masyarakat.

Berdasarkan dari latar belakang masalah di atas, maka peneliti tertarik untuk melakukan penelitian tentang "Hubungan lingkungan belajar dengan hasil belajar IPA siswa kelas V SDN 102028 Kampung Gelam Kabupaten Serdang”.

\section{Identifikasi Masalah}

Berdasarkan latar belakang masalah di atas, maka dapat diidentifikasi beberapa masalah dalam penelitian ini sebagai berikut:

1. Hasil belajar siswa rendah dikarenakan kurangnya kenyamanan siswa saat belajar.

2. Lingkungan sekolah di pinggir jalan yang menimbulkan kebisingan oleh deru kendaraan bermotor.

3. Kurangnya penggunaan media selama proses pembelajaran.

4. Sarana dan prasana belajar yang terbatas.

5. Kurangnya perhatian dan motivasi dari orang tua siswa.

Volume: 1 No. 1 Juli 2018 


\section{Batasan Masalah}

Dari latar belakang dan identifikasi masalah, maka penulis membatasi masalah yaitu "Hubungan lingkungan belajar dengan hasil belajar IPA siswa kelas V SDN 102028 Kampung Gelam Kabupaten Serdang Bedagai”.

\section{Rumusan Masalah}

Sesuai dengan batasan masalah di atas maka yang menjadi rumusan masalah dalam penelitian ini adalah: apakah terdapat hubungan lingkungan belajar dengan hasil belajar IPA siswa kelas V SDN 102028 Kampung Gelam Kabupaten Serdang Bedagai?.

\section{Tujuan Penelitian}

Adapun tujuan penelitian yaitu untuk mengetahui Hubungan lingkungan belajar dengan hasil belajar IPA siswa kelas V SDN 102028 Kampung Gelam Kabupaten Serdang Bedagai.

\section{Manfaat Penelitian}

Manfaat yang diperoleh dari penelitian ini adalah sebagai berikut:

1. Menambah pengetahuan penulis dalam bidang penelitian baik menyusun maupun observasi.

2. Bahan masukan bagi sekolah SDN 102028 Kampung Gelam Kabupaten Serdang Bedagai.

3. Sebagai salah satu informasi bagi siswa SDN 102028 Kampung Gelam Kabupaten Serdang Bedagai dalam hal hubungan lingkungan belajar dengan hasil belajar siswa.

\section{METODOLOGI PENELITIAN Desain Penelitian}

Penelitian ini merupakan penelitian kuantitatif korelasi, karena di dalam penelitian ini bertujuan untuk menemukan ada tidaknya hubungan lingkungan belajar dengan hasil belajar siswa di SDN 102028 Kampung Gelam Kabupaten Serdang Bedagai.

\section{Lingkungan Belajar}

Lingkungan belajar adalah tempat berlangsungnya kegiatan belajar yang mendapatkan pengaruh dari luar terhadap keberlangsungan kegiatan tersebut. Lingkungan yang merupakan sumber belajar memiliki pengaruh dalam proses pembelajaran.

\section{Hasil Belajar}

Hasil belajar merupakan perubahan yang terjadi dalam diri akibat belajar. Perubahan tersebut berupa perubahan dalam aspek kognitif, afektif, maupun psikomotornya. Hasil belajar dalam penelitian ini lebih difokuskan pada hasil belajar aspek kognitif yakni menggunakan nilai Ujian Tengah Semester (UTS) kelas V SDN 102028 Kampung Gelam dengan mata pelajaran IPA.

\section{Teknik Analisis Data}

Jadi untuk mengetahui apakah instrumen tersebut sudah benar mengukur apa yang seharusnya diukur dalam penelitian ini angket yang digunakan terlebih dahulu diuji validitasnya. Rumus yang digunakan untuk mengukur validitas angket yaitu rumus korelasi product moment sebagai berikut: 


$$
r_{x y}=\frac{N \sum X Y-\left(\sum X\right)\left(\sum Y\right)}{\sqrt{\left\{N \sum X^{2}-\left(\sum X\right)^{2}\right\}\left\{N \sum Y^{2}-\left(\sum Y\right)^{2}\right\}}}
$$

Keterangan :

$\mathrm{r}_{\mathrm{xy}}$

$\mathrm{N}$

$\Sigma X Y$

$\Sigma X$

$\Sigma \mathrm{Y}$
= Angka indeks korelasi " $\mathrm{r}$ " product moment

=Jumlah keseluruhan siswa

=Jumlah hasil perkalian antara skor Xdan Skor Y.

$=$ Jumlah seluruh skor $\mathrm{X}$

$=$ Jumlah seluruh skor $\mathrm{Y}$

Kriteria pengujian apabila ( $r_{\text {hitung }} \geq r_{\text {tabel }}$ ) pada taraf signifikan 5\%, atau $\alpha=0,05$ artinya alat ukur tersebut dapat dikatakan valid. Begitu juga sebaliknya ketika $\mathrm{r}_{\text {hitung }}<\mathrm{r}_{\text {tabel }}$ maka alat ukur tersebut tidak valid.

Peneliti menggunakan skala Guttman. Skala Guttman menurut Sugiyono (2010: 96) sebagai berikut: "Skala pengukuran dengan tipe ini akan di dapat jawaban yang tegas, yaitu ya-tidak, benar-salah, pernah-tidak pernah, positifnegatif". Lebih lanjut Sugiyono (2010: 26) menjelaskan "selain dapat dibuat dalam bentuk pilihan ganda, juga dapat dibuat dalam bentuk checklist. Jawaban dapat dibuat skor tertinggi satu dan terendah nol.

Tabel 3.4

Penskoran Angket

\begin{tabular}{|c|c|c|}
\hline \multirow{2}{*}{ Alternatif jawaban } & \multicolumn{2}{|c|}{ Penskoran } \\
\cline { 2 - 3 } & Positif & Negatif \\
\hline Ya & 1 & 0 \\
\hline Tidak & 0 & 1 \\
\hline
\end{tabular}

\section{HASIL PENELITIAN DAN PEMBAHASAN}

Setelah diuji hipotesis, maka untuk mengetahui seberapa besar kontribusi variabel $\mathrm{X}$ terhadap $\mathrm{Y}$ maka harus dihitung dahulu koefisien determinasinya. Hasil nilai koefisien determinasi dalam penelitian ini adalah $30 \%$. Hal ini mengandung pengertian bahwa lingkungan belajar yang diberikan untuk hasil belajar tergolong rendah.

Penelitian ini merupakan jenis penelitian korelasional untuk menguji hubungan antara variabel lingkungan sekolah terhadap hasil belajar siswa yang dilakukan di SD Negeri Gugus Wibisono Kecamatan Jati Kabupaten Kudus. Pengujian hipotesis dalam penelitian ini menggunakan uji korelasi product moment yaitu untuk mengetahui bagaimana hubungan antara lingkungan sekolah dengan hasil belajar siswa. Persyaratan yang harus dipenuhi sebelum uji korelasi yaitu distribusi data harus normal (uji normalitas) yang dianalisis menggunakan program SPSS versi 21.

Pada hasil penelitian berdasarkan analisis deskriptif mengenai lingkungan belajar pada siswa kelas V SDN 102028 Kampung Gelam Kabupaten Serdang Bedagai diperoleh rata-rata secara keseluruhan sebesar $47 \%$ dengan kriteria kurang baik. Lingkungan belajar merupakan segala sesuatu yang ada di sekitar kita baik fisik maupun nonfisik dimana sangat berpengaruh terhadap tingkah laku seseorang khususnya anak didik di dalam lembaga pendidikan formal maupun non formal yang melaksanakan pendidikan untuk kegiatan pengajaran 
bagi siswa dalam mengembangkan potensinya. Lingkungan belajar meliputi: (1) lingkungan keluarga antara lain: kondisi tempat belajar di rumah, dukungan dan motivasi dari orangtua serta kelengkapan fasilitas belajar anak di rumah. (2) lingkungan sekolah antara lain: kondisi gedung sekolah, sarana dan prasarana media belajar siswa saat mengikuti proses belajar mengajar disekolah, kelengkapan fasilitas sekolah yang mendukung kenyamanan siswa dalam belajar serta disiplin sekolah. (3) lingkungan sosial antara lain: hubungan siswa dengan siswa, hubungan siswa dengan guru, keadaan sekitar sekolah,

Selanjutnya maka dapat dilakukan perhitungan statistik korelasi dari nilai-nilai yang diperoleh melalui data-data penelitian yaitu dari hasil perhitungan statistik hubungan lingkungan belajar dengan hasil belajar siswa diperoleh $r_{\text {hitung }}$ $=0,552>r_{\text {tabel }}=0,381$ hal ini menunjukkan hubungan yang kuat dengan hasil belajar. Hasil korelasi kemudian diuji hipotesisnya dengan menggunakan uji t. Hasil perhitungan menunjukkan bahwa $t_{\text {hitung }}=3,30>t_{\text {tabel }}$ 0,684 dengan demikian hipotesi yang dikemukakan diterima atau dengan kata lain ada hubungan yang positif dan signifikan antara lingkungan belajar dengan hasil belajar, karena dapat diterima $t_{\text {hitung }}$ lebih besar dari $t_{\text {tabel }}$.

Sedangkan untuk uji normalitas digunakan dengan tujuan untuk mengetahui apakah data dalam penelitian tersebut berdistribusi normal atau tidak. Teknik yang digunakan untuk pengujian normalitas yaitu dengan menggunakan uji Kolmogorov-Smirnov (K-S). Angka signifikansi uji kolmogorov-smirnov sig. > 0,05 menunjukkan bahwa data terdistribusi normal. Sebaliknya jika signifikansi uji kolmogorov-smirnov sig. $<0,05$ maka data tersebut tidak normal. Dari perhitungan analisis statistik uji normalitas angket sebesar uji kolmogorovsmirnov sig.0,559 > 0,05 maka data lingkungan berdistribusi normal.

\section{Penutup Simpulan}

Berdasarkan hasil penelitian tentang hubungan antara lingkungan belajar dengan hasil belajar pada siswa kelas V SDN Kampung Gelam Kabupaten Serdang Bedagai dapat disimpulkan bahwa ada hubungan yang positif dan signifikan antara lingkungan belajar dengan hasil belajar siswa. Artinya hipotesis yang diajukan dalam penelitian yaitu karena dapat diterima $t_{\text {hitung }}=3,30>t_{\text {tabel }}$ =0,684 Ha (terdapat hubungan yang signifikan antara lingkungan sekolah dengan hasil belajar siswa kelas V SDN 102028 Kampung Gelam Kabupaten Serdang Bedagai diterima, sedangkan Ho (tidak terdapat hubungan yang signifikan antara lingkungan belajar dengan hasil belajar pada siswa kelas V SD SDN 102028 Kampung Gelam Kabupaten Serdang Bedagai ditolak.

Persentase sumbangan kontribusi variabel lingkungan belajar dengan hasil belajar siswa tersebut sebesar 30\%, diketahui bahwa kontribusi lingkungan belajar sangat mempengaruhi hasil belajar siswa. Penelitian ini membuktikan bahwa terdapat hubungan yang positif antara lingkungan belajar dengan hasil belajar siswa. Semakin kurang baik lingkungan sekolah yang digunakan untuk kegiatan belajar akan semakin menurun hasil belajar siswa. Oleh karena itu, dengan penelitian ini di SDN 102028 Kampung Gelam Kabupaten Serdang Bedagai diharapkan dapat membantu meningkatkan kualitas pendidikan. 


\section{Saran}

Berdasarkan hasil analisis dan pembahasan dalam penelitian ini, maka dapat dikemukakan saran-saran sebagai berikut:

1. Kepala sekolah hendaknya, lebih memperhatikan keluhan dari guru dan siswa seperti sumber belajar atau alat belajar yang dibutuhkan dalam proses pembelajaran.

2. Bagi guru diharapkan untuk lebih memotivasi siswa dengan menciptakan pembelajaran kreatif yang dapat menimbulkan minat belajar siswa. Di samping itu guru juga harus meningkatkan kualitas diri dengan memberikan teladan dan bimbingan kepada siswa.

3. Bagi peneliti lain, untuk dapat dijadikan sebagai acuan dalam meneliti lebih lanjut.

\section{DAFTAR PUSTAKA}

Arikunto, Suharsimi. 2013. Prosedur Penelitian Suatu Pendekatan Praktik. Jakarta: Rineka Cipta.

Depdikbud. 2008. Kamus Besar Bahasa Indonesia. Jakarta : Balai Pustaka Hamalik, Oemar. 2014. Kurikulum Dan Pembelajaran. Jakarta: Bumi Aksara. Hasbullah. 2012. Dasar-Dasar Pendidikan. Jakarta: Raja Wali Pers.

Khairani, Makmun. 2013. Psikologi Belajar. Yogyakarta: Aswaja Pressindo Mariyana, Rita dkk. 2010. Pengelolaan lingkungan belajar. Jakarta: Kencana Mudjiono dan Dimyati. 2009. Belajar Dan Pembelajaran. Jakarta : Pt Rineka Cipta

Muhibbinsyah. 2017. Psikologi Pendidikan. Bandung: PT Remaja Rosdakarya Offset

Hamalik, Oemar. 2013. Proses belajar mengajar. Jakarta: Bumi Aksara

Purwanto. 2017. Evaluasi Hasil Belajar. Yogyakarta:Pustaka Pelajar

Rusman. 2013. Belajar dan Pembelajaran Berbasis Komputer. Bandung: Alfabeta

Sadirman. 2016. Interaksi Dan Motivasi Belajar Mengajar. Jakarta : Pt Raja Grafindo Prasada

Sagala, Syaiful. 2009. Konsep Dan Makna Belajar. Bandung : Alfabeta

Sanjaya, Wina. 2014. Media Komunikasi Pembelajaran. Jakarta : Prenada Media

Slameto. 2010. Belajar Dan Faktor-Faktor Yang Mempengaruhi. Jakarta: Pt Rineka Cipta

Sudijono, Anas. 2011. Pengantar Statistik Pendidikan. Jakarta : Pt Raja Grafindo Persada

Sugiyono. 2010. Metode Penelitian Kuantitatif, Kualitatif Dan R Dan D. Bandung : Alfabeta

Suhartono, Suparlan. 2006. Filsafat Pendidikan. Jogjakarta : Ar-Ruzz Media.

Susanto, Ahmad. 2013. Teori Belajar Pembelajaran. Jakarta : Prenamedia Grop.

Syah, Muhibbin. 2017. Psikologi pendidikan. Bandung: PT Remaja Rosdakarya Offset

Syarif, Kemali. 2013. Perkembangan Peserta Didik. Medan : Unimed.

Uno, Lamatenggo (Penterjemah). 2016. Landasan Pendidikan. Jakarta : Bumi Aksara

Yusuf, Syamsu. 2016. Psikologi Perkembangan Anak Remaja. Bandung: Pt Remaja Rosdakarya Offset 